\title{
Influence of surface treatment on shear bond strength of orthodontic brackets
}

Ione Helena Vieira Portella Brunharo¹, Daniel Jogaib Fernandes², Mauro Sayão de Miranda³, Flavia Artese ${ }^{4}$

Introduction: The shear bond strength of orthodontic brackets bonded to micro-hybrid and micro-particulate resins under different surface treatment methods was assessed. Methods: Two hundred and eighty test samples were divided into 28 groups $(n=10)$, where 140 specimens were filled with Durafill micro-particulate resin and 140 with Charisma composite. In 140 samples, a coupling agent (silane) was applied. The surface treatment methods were: Phosphoric and hydrofluoric acid etching, sodium bicarbonate and aluminum oxide blasting, stone and burs. A Universal Instron Machine was used to apply an occlusal shear force directly to the resin composite bracket surface at a speed of $0.5 \mathrm{~mm} / \mathrm{min}$. The means were compared using analysis of variance and multivariate regression to assess the interaction between composites and surface treatment methods. Results: Means and standard deviations for the groups were: Sodium bicarbonate jet $11.27 \pm 2.78$; burs $9.26 \pm 3.01$; stone $7.95 \pm 3.67$; aluminum oxide blasting 7.04 \pm 3.21 ; phosphoric acid 5.82 \pm 1.90 ; hydrofluoric acid $4.54 \pm 2.87$, and without treatment $2.75 \pm 1.49$. An increase of $1.94 \mathrm{MPa}$ in shear bond strength was seen in Charisma groups. Silane agent application reduced the Charisma shear bond strength by $0.68 \mathrm{Mpa}$, but increased Durafill means for bicarbonate blasting (0.83), burs (0.98) and stone drilling (0.46). Conclusion: The sodium bicarbonate blasting, burs and stone drilling methods produced adequate shear bond strength and may be suitable for clinical use. The Charisma micro hybrid resin composite showed higher shear bond means than Durafill micro particle composite.

Keywords: Shear bond strength. Dental materials. Orthodontic brackets. Orthodontics.

Introdução: foram avaliadas as forças de cisalhamento após colagem de braquetes ortodônticos em superfícies resinosas microparticuladas ou micro-híbridas, após diferentes tratamentos de superfície. Métodos: foram utilizados 280 corpos de prova, divididos em grupos de 10 elementos cada, sendo 140 preenchidos com resina microparticulada Durafill e 140 com resina micro-híbrida Charisma. Os tratamentos de superfície envolveram: ácido fosfórico, ácido fluorídrico, jato de bicarbonato de sódio, jato de óxido de alumínio, pedra e broca. A silanagem foi utilizada em metade dos grupos. O cisalhamento foi realizado com a máquina universal de testes EMIC DL $10000 \mathrm{MF}$, com célula de 10kg e velocidade de $0,5 \mathrm{~mm} / \mathrm{min}$. As comparações entre as forças de cisalhamento foram obtidas por meio da análise de variância, e o grau de interação entre os tipos de compósito e o preparo de superfície foram obtidos por meio de uma regressão multivariada. Resultados: as médias e desvios-padrão foram: jato de bicarbonato $=11,27 \pm 2,78$; broca $=9,26 \pm 3,01$; pedra $=7,95 \pm 3,67 ;$ jato de óxido de alumínio $=7,04 \pm 3,21$; ácido fosfórico $=5,82 \pm 1,90$; ácido fluorídrico $=4,54 \pm 2,87$; e sem preparo $=2,75 \pm 1,49$. Um acréscimo de $1,94 \mathrm{MPa}$ foi obtido com o uso do compósito Charisma. A silanagem reduziu em $0,68 \mathrm{MPa}$ as médias do compósito Charisma, e aumentou o Durafill com uso do jato de bicarbonato $(0,83)$, broca $(0,98)$ e pedra $(0,46)$. Conclusão: os preparos com jato de bicarbonato, broca e pedra obtiveram médias de forças apropriadas para colagem. O compósito Charisma apresentou forças de maior intensidade que as da resina Durafill.

Palavras-chave: Resistência ao cisalhamento. Materiais dentários. Braquetes ortodônticos. Ortodontia.

${ }^{1} \mathrm{PhD}$ in Orthodontics, Visiting Professor, Department of Preventive and Community Dentistry, UERJ.

${ }^{2} \mathrm{PhD}$ in Orthodontics, UERJ.

${ }^{3}$ Adjunct Professor, Department of Restorative Dentistry, UERJ.

${ }^{4}$ Adjunct Professor, Department of Preventive and Community Dentistry Orthodontics, UERJ.

» The authors report no commercial, proprietary or financial interest in the products or companies described in this article.
How to cite this article: Brunharo IHVP, Fernandes DJ, Miranda MS, Artese F. Influence of surface treatment on shear bond strength of orthodontic brackets. Dental Press J Orthod. 2013 May-June;18(3):54-62.

Submitted: September 19, 2009 - Revised and accepted: April 12, 2010

Contact address: Ione Helena Vieira Portella Brunharo Rua Largo do Machado 54/501 - Flamengo - Rio de Janeiro/RJ - Brazil CEP: 22.221-020 - E-mail: ioneportella@yahoo.com.br 


\section{INTRODUCTION}

Adult patients undergoing orthodontic treatment often have teeth restored with resin composites commonly used for esthetic purposes and for restorations. ${ }^{1,2}$ This type of material is also widely found in the mouths of young patients due to a high incidence of trauma during permanent dentition (30\%). ${ }^{3}$

The use of dental composites for bonding orthodontic brackets to enamel is convenient as it allows careful positioning of the orthodontic accessories while promoting bond strength capable of withstanding tooth movement during application of different types of forces. The literature is rich in methods and properties used in the direct bonding of orthodontic metal accessories to ceramic surfaces. ${ }^{4,5,6}$ However, few studies have been conducted to evaluate this procedure on composite restorations. Therefore, there is great clinical demand for an effective technique capable of allowing teeth restored with resin composite to be subjected to different types of force application.

In order to develop an efficient method for bonding brackets onto resin composite surfaces it is necessary to learn about the factors that directly influence the success of the procedure, such as type of resin composite (hybrid or micro-particulate) and bond strength. Research carried out by Schwartz, Tyas and West ${ }^{7}$ and Lai, Woods and Tyas, ${ }^{8}$ demonstrated that metallic brackets bonded to hybrid and micro-particulate restorative composites could withstand 7.8 MPa of shear force, which according to Lopez ${ }^{9}$ would be sufficient to ensure a successful bond in clinical practice.

Several methods based on the repairing technique of resin composites have been reported as capable of improving bond strength. These include acid etching, ${ }^{10,11}$ air abrasion $^{12,13}$ and the use of solvents and silanes. ${ }^{14,15}$ However, no consensus has yet been reached regarding the results obtained with different procedures hence, this study. The aim of this study, therefore, was to assess the bond strength resulting from the direct bonding of orthodontic brackets to surfaces composed of micro-particulate and micro-hybrid restorative materials subjected to different chemical and physical surface treatment methods.

\section{MATERIAL AND METHODS}

Two hundred and eighty cylinders were fabricated from acrylic (specimens) with $25 \mathrm{~mm}$ diameter and $5 \mathrm{~mm}$ in height, with an $8 \mathrm{~mm}$ diameter and $1.5 \mathrm{~mm}$ depth hole, with grooves on the bottom for increased retention of the resin composite. Of these, 240 were used for surface treatment testing and the remaining for the control group. In order to prevent the Transbond XT adhesive (3M/Unitek, Monrovia, CA, USA) from flowing and thereby affecting the yield strength values on shearing, the bonding area was bounded with tape prior to surface preparation.

Two types of resin composites were tested: (a) Durafill resin composite (HeraeusKulzer, Hanau, Germany), and (b) Charisma micro hybrid resin composite (HeraeusKulzer, Hanau, Germany). These materials were all placed in one go to reduce the incorporation of air bubbles, and light cured for 40 seconds, 20 at the top and 20 at the bottom. A glass slide was used for compression and homogenization of the material (Fig 1). Ortholux XT Visible Light Curing Unit (3M Unitek, Monrovia, CA, USA) was used, and had its light intensity measured prior to curing at each stage, in all groups (Optilux Radiometer Model 100, SDS Care, Danbury, CT, USA). The intensity found was $450 \pm 10 \mathrm{~mW} / \mathrm{cm}^{2}$. Additionally, the bonding procedures were all performed in the same environment and with a $1 \mathrm{kVA}$ voltage stabilizer connected to the curing light. The specimens were stored in plastic containers with distilled water, covered with an opaque lid and kept in an oven at $37 \pm 1^{\circ} \mathrm{C}$ for 7 days for aging.

\section{Sample group composition}

The specimens were divided into 28 groups of 10 elements, separated according to the type of surface treatment, type of resin composite and the use / non-use of silane (Table 1). The resinous surfaces were treated by the following agents: $37 \%$ phosphoric acid (Dental G Conditioner, Dentsply, Petrópolis, RJ) for

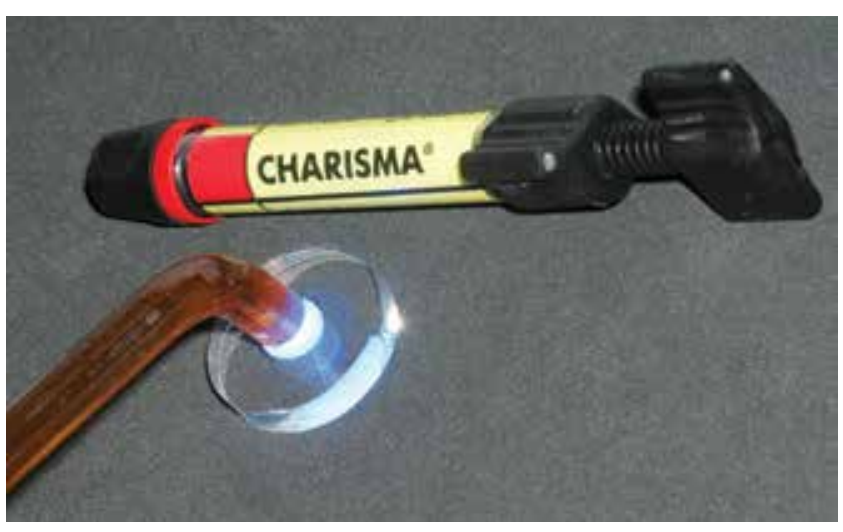

Figure 1 - Light curing of specimens filled with resin composite. 
Table 1 - Presentation of groups, types of chemical surface treatment, use or non-use of silane, and type of resin composite used.

\begin{tabular}{|c|c|c|c|}
\hline Groups & Surface treatments & Silane application & Resin \\
\hline 1 & Phosphoric acid no Durafill & No & Durafill \\
\hline 2 & Phosphoric acid with Durafill & Yes & Durafill \\
\hline 3 & Hydrofluoric acid no Durafill & No & Durafill \\
\hline 4 & Hydrofluoric acid with Durafill & Yes & Durafill \\
\hline 5 & Aluminum oxide blasting no Durafill & No & Durafill \\
\hline 6 & Aluminum oxide blasting with Durafill & Yes & Durafill \\
\hline 7 & Sodium bicarbonate no Durafill & No & Durafill \\
\hline 8 & Sodium bicarbonate blasting with Durafill & Yes & Durafill \\
\hline 9 & Mounted stone no Durafill & No & Durafill \\
\hline 10 & Mounted stone with Durafill & Yes & Durafill \\
\hline 11 & Diamond bur no Durafill & No & Durafill \\
\hline 12 & Diamond bur with Durafill & Yes & Durafill \\
\hline 13 & No treatment no Durafill & No & Durafill \\
\hline 14 & No treatment with Durafill & Yes & Durafill \\
\hline 15 & Phosphoric acid no Charisma & No & Charisma \\
\hline 16 & Phosphoric acid with Charisma & Yes & Charisma \\
\hline 17 & Phosphoric acid no Charisma & No & Charisma \\
\hline 18 & Hydrofluoric acid with Charisma & Yes & Charisma \\
\hline 19 & Aluminum oxide blasting no Charisma & No & Charisma \\
\hline 20 & Aluminum oxide blasting with Charisma & Yes & Charisma \\
\hline 21 & Sodium bicarbonate blasting no Charisma & No & Charisma \\
\hline 22 & Sodium bicarbonate blasting with Charisma & Yes & Charisma \\
\hline 23 & Mounted stone no Charisma & No & Charisma \\
\hline 24 & Mounted stone with Charisma & Yes & Charisma \\
\hline 25 & Diamond bur no Charisma & No & Charisma \\
\hline 26 & Diamond bur with Charisma & Yes & Charisma \\
\hline 27 & No treatment no Charisma & No & Charisma \\
\hline 28 & No treatment with Charisma & Yes & Charisma \\
\hline
\end{tabular}

30 seconds (Fig 2A); 10\% hydrofluoric acid (Porcelain Conditioner, Dentsply, Petrópolis, RJ) for 2 minutes (Fig 2B); aluminum oxide blasting (blaster manufactured by Bio Art dental equipment Ltd, São Carlos, São Paulo, Brazil, 50-micron particles) (Fig 2C) and bicarbonate blasting (Profi II Ceramic, Dabi Atlante, Ribeirão Preto, São Paulo, Brazil, 60 pounds) (Fig 2D); mounted cylindrical stone (Jon, São Paulo, SP, Brazil) (Fig 2E) and high speed cylindrical diamond bur (3101, KG Sorensen, Barueri, SP, Brazil) (Fig 2F). In the two latter groups unidirectional grooves were observed by stereomicroscopy. The cleaning and drying procedures were similar in all other groups, and consisted in air/water sprays for 30 seconds followed by drying with air for another 30 seconds.

Thereafter, maxillary central incisor metallic brackets (standard edgewise) (Dental Morelli Ltda., Sorocaba,
SP, Brazil) with $3.8 \times 3.6 \mathrm{~mm}$ base and $0.022 \times 0.030$-in slot were bonded. The brackets were bonded to the composite restorative system of the specimens using Transbond XT orthodontic adhesive system according to manufacturer's specifications (Fig 3).

In groups where silane (Angelus, Londrina, PR) was applied, a microbrush (KG Sorensen Indústria and Comércio Ltda., Barueri, SP, Brazil) was used, and after a 1 minute interval, was homogenized by air jet for $3 \mathrm{sec}-$ onds as well as the primer (Transbond XT Primer, 3M Unitek, Monrovia, CA, USA), which was applied with a microbrush and also homogenized by air jet.

Transbond XT adhesive system was applied to the base of the bracket and positioned on the surface of the pretreated resin composite. The brackets were pressed lightly avoiding any movement, with the purpose of causing the adhesive paste to flow and allow for the removal of adhesive flash with 

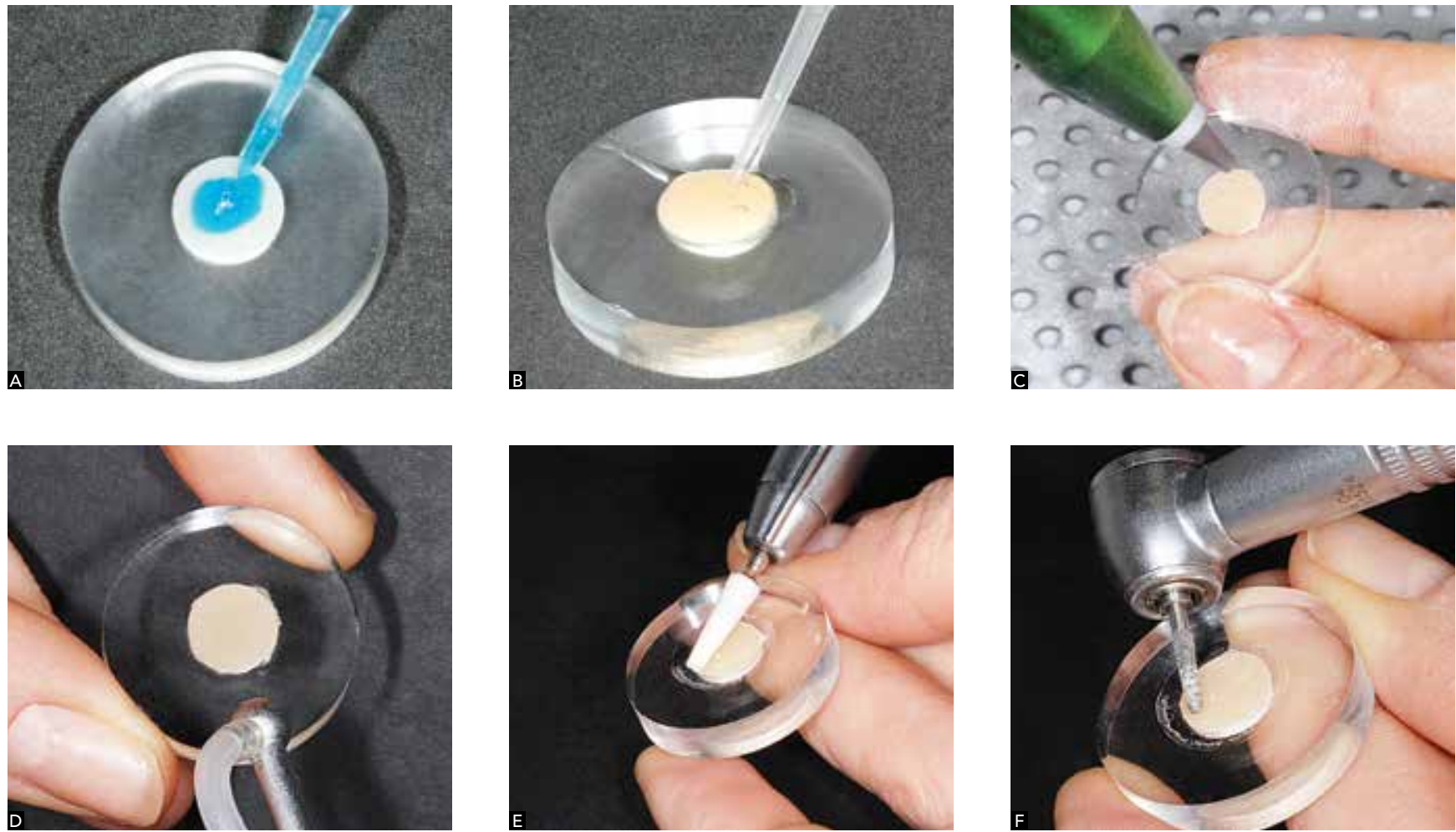

Figure 2 - Surface treatment using: A) 37\% phosphoric acid, B) hydrofluoric acid, C) aluminum oxide blasting, D) sodium bicarbonate blasting, E) mounted stone, and F) diamond bur.

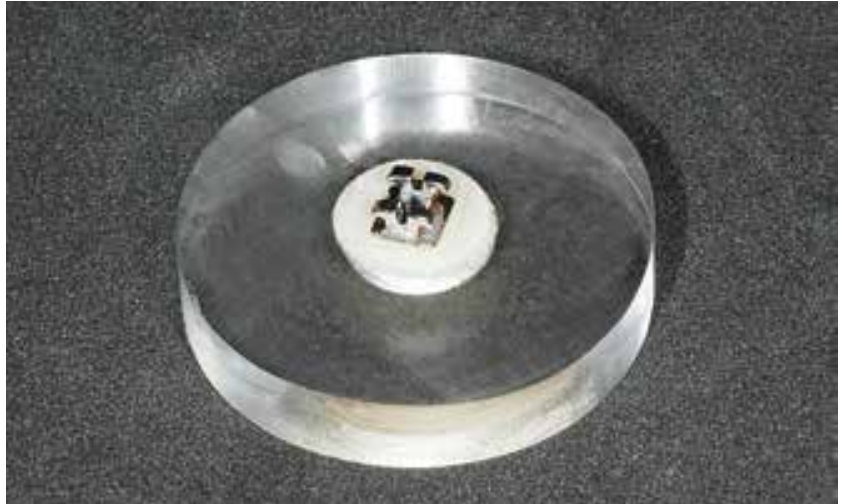

Figure 3 - Orthodontic Brackets bonded with Transbond XT light-cured resin onto previously treated surfaces.

an explorer \#5 (DUFLEX, Petrópolis, RJ, Brazil). Light curing was performed on the whole set for 20 seconds (10 seconds on the mesial and 10 seconds on the distal surface). After bracket bonding, the same storage protocol described above was performed. The specimens were then once again stored in distilled water at $37^{\circ} \mathrm{C}$ for 7 days for aging.

\section{Shear test}

For the mechanical shear strength test a universal testing machine (EMIC DL 10000 MF cell Trd 21) owned by the Laboratory of Biomaterials at the Military Engineering Institute was used. The specimens are fastened to a device so that the bracket base was kept parallel to the tip of the chisel (Fig 4). Tests were performed with a load cell of $10 \mathrm{~kg}$ at a speed of $0.5 \mathrm{~mm} / \mathrm{min},{ }^{16}$ and data recorded by a computer program (TESC version 3.04, Pinhais, PR, Brazil)

\section{Adhesive remnant index (ARI)}

After shearing the specimens, the bases of the brackets and the resin surfaces were examined in a stereomicroscope with 20x magnification. Adhesive remnant index (ARI) was categorized as follows: Score 0 (no adhesive present on the bracket bases); 1 (less than half); 2 (more than half) and 3 (the entire adhesive remained on the bracket base). ${ }^{17}$ A descriptive analysis of the data with means, medians and standard deviations was carried out. Comparisons between shear force means were made using analysis of variance (ANOVA) with Scheffe correction for multiple comparisons. Kruskall-Wallis test was used for multiple comparisons between the scores, complemented by Mann-Whitney test.

\section{RESULTS}

The mean shear force values ranged between $2.30 \mathrm{MPa}$ and 12.02 MPa, whereas the groups treated with acid etch- 


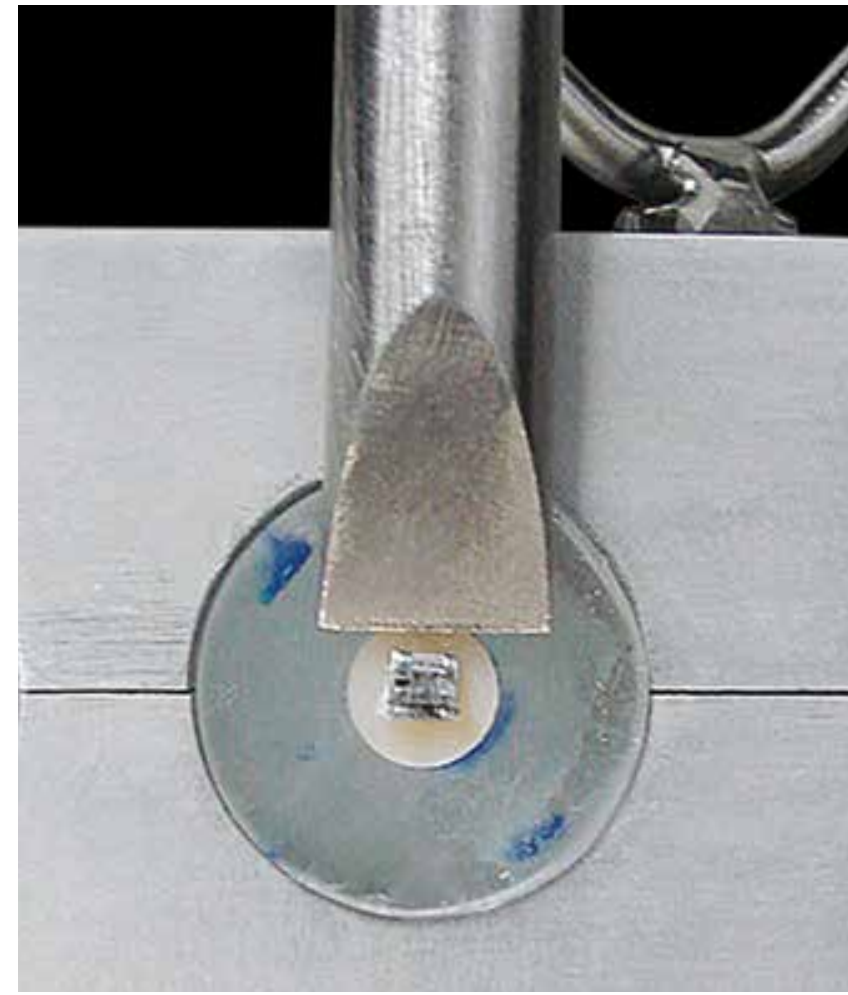

Figure 4 - Bracket shearing in an Emic DL 10000 MF universal testing machine. Note the metallic support for fixation of specimens.

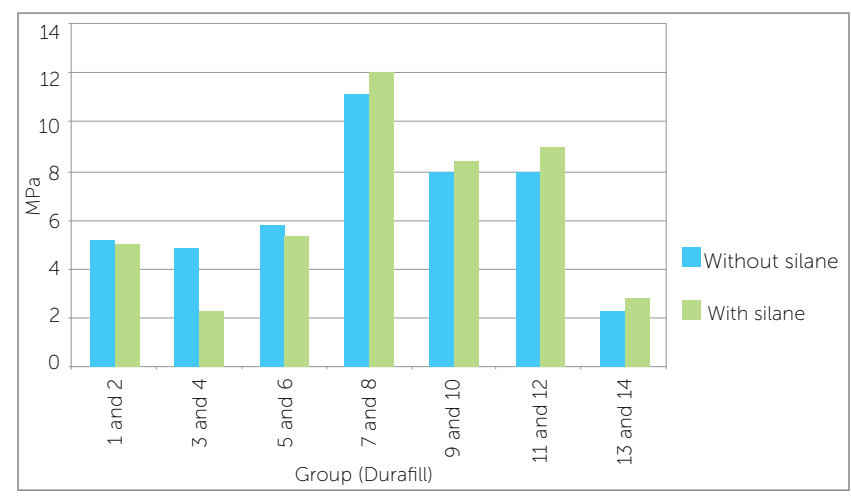

Figure 5 - Diagram showing shearing forces of specimens filled with Durafill resin arranged according to the use or non-use of silane.

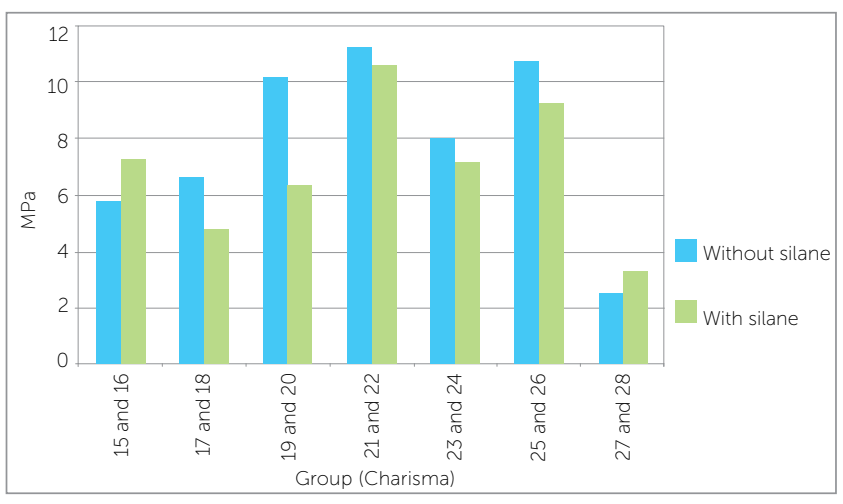

Figure 6 - Diagram showing shearing forces of specimens filled with Charisma resin arranged according to the use or non-use of silane. ing attained lower values than those observed in the groups treated by blasting and bur/stone. In specimens filled with Durafill resin, silane application improved the means after treatment with bicarbonate blasting, bur and stone, but higher standard deviations were observed (Fig 5). Regarding Charisma, the highest mean was obtained with bicarbonate blasting without silane, although the application of silane worsened the mean yield strength values, with the exception of phosphoric acid etching (Fig 6). The stone without silane group showed the largest standard deviation followed by etching with hydrofluoric acid without silane. The brackets in the control groups of both resin composites had lower shear strength scores (Table 2).

Bivariate analyses showed that there are differences between the means of the groups, i.e., Durafill and Charisma, in terms of surface preparation and silane application. The Charisma group obtained higher means than the Durafill group. The resins tested exhibited their best performance with bicarbonate blasting, and the latter group with diamond burs. The effects produced - regardless of the type of resin composite (Durafill or Charisma) - types of surface preparation and use of silane were assessed by multiple linear regression. Analysis of the model showed significant interaction between type of composite and type of preparation (Table 2).

In trivariate analysis, the Charisma group treated with hydrofluoric acid (Fl) without silane (5.85 MPa) was used as a basis for comparison. Compared to this group, all other surface preparations were significantly different in terms of specimen shear values, except for the use of phosphoric acid ( $p=0.23$ ). Charisma tests showed that the best surface preparation was bicarbonate blasting (5.42 MPa) followed by the use of burs (4.52 $\mathrm{MPa})$, aluminum oxide (3.01 MPa), and stone (2.23 $\mathrm{MPa})$, compared to hydrofluoric acid. In the control group, the non-use of silane decreased shear strength by 1.94 MPa compared to the use of hydrofluoric acid under the same conditions (Table 2).

In Table 3, the multivariate linear regression model highlights the interaction between the composite type and type of surface preparation variables. Charisma with hydrofluoric acid was used as a basis for comparison, where bonding performed with silane application reduced bracket adhesion, i.e., $0.68 \mathrm{MPa}(\mathrm{p}=0.05)$. It was found that the use of Durafill with the same surface preparation, hydrofluoric acid resin without silane, compared to Charisma, caused the shear force to worsen 
Table 2 - Description of mean and standard deviation values of shear forces comprising 4 characteristics. Analysis of Variance (ANOVA) with Scheffe correction.

\begin{tabular}{|c|c|c|c|}
\hline & Mean \pm SD & Size Sample & $p$ value \\
\hline \multicolumn{4}{|c|}{ Composite in restoration } \\
\hline Charisma & $7.45 \pm 3.91$ & 130 & \multirow{2}{*}{0.028} \\
\hline Durafill & $6.44 \pm 3.72$ & 130 & \\
\hline \multicolumn{4}{|c|}{ Restoration composite preparation type } \\
\hline Hydrofluoric acid & $4.54^{\text {a.b.c.d }} \pm 2.87$ & 40 & \multirow{7}{*}{$<0.00$} \\
\hline Phosphoric acid & $5.82^{\text {ef.g }} \pm 1.90$ & 40 & \\
\hline Bur & $9.26^{\text {ae.h }} \pm 3.01$ & 40 & \\
\hline Bicarbonate blasting & $11.27^{\text {b.d.fi.j.k }} \pm 2.78$ & 40 & \\
\hline Aluminum oxide & $7.04^{\text {ci.l. }} \pm 3.21$ & 40 & \\
\hline Stone & $7.95^{\mathrm{dj} \cdot \mathrm{m}} \pm 3.67$ & 40 & \\
\hline None & $2.75^{\text {e.g.h.k.l.m }} \pm 1.49$ & 20 & \\
\hline \multicolumn{4}{|l|}{ Presence of silane } \\
\hline No & $7.99^{\mathrm{ab}} \pm 3.81$ & 120 & \multirow{2}{*}{$<0.00$} \\
\hline Yes & $6.70^{b c} \pm 3.61$ & 120 & \\
\hline Total & $6.95 \pm 3.84$ & 260 & - \\
\hline
\end{tabular}

Pairs of means with same letters show statistically significant differences at $5 \%$ level after correction using Scheffe's multiple comparisons test.

by up to $1.94 \mathrm{Mpa}$ (Table 3). Although Durafill resulted in smaller magnitudes than Charisma, the combined use of Durafill with bicarbonate blasting resulted in an additional increase in shear force (2.63 MPa) compared with the observed data (means), when the use of bicarbonate blasting and Charisma were combined. The stone group also had a significant increase of $2.37 \mathrm{MPa}$ $(\mathrm{p}=0.05)$ relative to the comparison group, Charisma and hydrofluoric acid without silane (Table 3).

Statistical differences between specimen ARI scores in the various groups are depicted in Table 4. Analysis of specimen ARI scores after debracketing revealed a tendency of Charisma group specimens with surfaces treated by hydrofluoric acid, aluminum oxide, mounted stone (with application of silane) and diamond burs (without silane) to exhibit failures at the adhesive/ bracket interface. In Durafill groups, the same interface failure was observed in specimens conditioned with hydrofluoric acid and aluminum oxide (without silane application). Charisma groups treated by phosphoric acid, bicarbonate blasting and use of stone (without silane application) and burs (with silane) tended to show failures at the adhesive/specimen interface. The same behavior was observed in the Durafill groups conditioned by phosphoric acid, bicarbonate blasting and after use of stone and diamond burs (Table 4).

The use of silane did not produce ARI differences in many groups, except for 3 specimen groups filled with
Charisma, and surfaces treated by hydrofluoric acid, mounted stone and diamond burs.

\section{DISCUSSION}

The shear force of both types of resin composites tested were considered different, and were influenced by the vast majority of surface preparations analyzed. According to Swift, Valley and Boyer ${ }^{10}$ the shear force of hybrid resin bonding was higher than that of microparticulate resin, although their study did not test adhesion using orthodontic brackets.

Most studies reviewed tested the bond strength of different types of resin in procedures to repair esthetic restorations. In these cases, several authors ${ }^{18,19,20,21}$ reported the need to etch the composite in order to enhance its adhesiveness. In this study it was found that the effect of surface preparation on both resin composite types were similar to procedures to repair restorations.

Hydrofluoric acid treatment produced a significant decrease in shear force compared to blasting procedures (aluminum oxide and bicarbonate) or grooved surface (bur and stone) (Tables 2 and 3). This finding corroborates works reported in the literature. ${ }^{16,22,23}$

Swift, Valley and Boyer ${ }^{10}$ stated that the effect of hydrofluoric acid is related to its percentage, size and type of inorganic composition. Therefore, depending on the type of resin composite, the effect of hydrofluoric acid may alter the effect of cohesion between 
Table 3 - Coefficients of multivariate regression with the shear force interaction terms between composite and preparation

\begin{tabular}{|c|c|c|c|c|c|c|c|c|}
\hline & & \multirow{2}{*}{$\begin{array}{l}\text { Force } \\
\text { (MPa) }\end{array}$} & \multicolumn{2}{|c|}{ Cl $95 \%$} & \multirow{2}{*}{ p-valor } & \multicolumn{3}{|c|}{ Variable combination description } \\
\hline & & & Lower & Upper & & Composite & Adhesive & Preparation \\
\hline $\begin{array}{l}\text { Group used for } \\
\text { comparison }\end{array}$ & & 5.85 & 4.62 & 7.08 & - & Hydrofluoric acid & Without silane & Charisma \\
\hline Effect of adhesive & With silane & -0.68 & -1.37 & 0.00 & 0.05 & Hydrofluoric acid & With silane & Charisma \\
\hline Composite effect & Durafill & -1.94 & -3.61 & -0.27 & 0.02 & Hydrofluoric acid & Without silane & Durafill \\
\hline \multirow{6}{*}{ Preparation effect } & Phosphoric acid & 1.02 & -0.65 & 2.69 & 0.23 & Phosphoric acid & Without silane & Charisma \\
\hline & Bur & 4.51 & 2.84 & 6.19 & 0.00 & Bur & Without silane & Charisma \\
\hline & Bicarbonate blasting & 5.42 & 3.74 & 7.09 & 0.00 & Bicarbonate blasting & Without silane & Charisma \\
\hline & Aluminum oxide & 3.01 & 1.34 & 4.68 & 0.00 & Aluminum oxide & Without silane & Charisma \\
\hline & Stone & 2.23 & 0.55 & 3.90 & 0.01 & Stone & Without silane & Charisma \\
\hline & None & -1.94 & -3.84 & -0.05 & 0.05 & None & Without silane & Charisma \\
\hline \multirow{6}{*}{$\begin{array}{l}\text { Interaction } \\
\text { Durafill versus }\end{array}$} & Phosphoric acid & 0.52 & -1.84 & 2.89 & 0.67 & Phosphoric acid & Without silane & Durafill \\
\hline & Bur & 0.42 & -1.94 & 2.79 & 0.73 & Bur & Without silane & Durafill \\
\hline & Bicarbonate blasting & 2.63 & 0.26 & 4.99 & 0.03 & Bicarbonate blasting & Without silane & Durafill \\
\hline & Aluminum oxide & -1.01 & -3.38 & 1.35 & 0.40 & Aluminum oxide & Without silane & Durafill \\
\hline & Stone & 2.37 & 0.01 & 4.74 & 0.05 & Stone & Without silane & Durafill \\
\hline & None & 1.61 & -0.76 & 3.97 & 0.18 & None & Without silane & Durafill \\
\hline
\end{tabular}

Table 4 - Differences between group scores (ARI)

\begin{tabular}{|c|c|}
\hline Group & Differed from groups \\
\hline 1 & $4,19,20,24,26$ \\
\hline 2 & $4,19,20,24,26$ \\
\hline 3 & - \\
\hline 4 & $8,9,12,13,14,18,23,27,28$ \\
\hline 5 & $8,9,12,13,14,23,27$ \\
\hline 6 & - \\
\hline 7 & 20 \\
\hline 8 & $19,20,24,26$ \\
\hline 9 & $19,20,24,26$ \\
\hline 10 & - \\
\hline 11 & 20 \\
\hline 12 & $19,20,24,26$ \\
\hline 13 & $19,20,24,26$ \\
\hline 14 & $19,20,24,26$ \\
\hline 15 & - \\
\hline 16 & - \\
\hline 17 & $18^{*}$ \\
\hline 18 & 19,20 \\
\hline 19 & $23,27,28$ \\
\hline 20 & $23,27,28$ \\
\hline 21 & - \\
\hline 22 & - \\
\hline 23 & $24^{*}, 26$ \\
\hline 24 & 27 \\
\hline 25 & $26^{*}$ \\
\hline 26 & 27 \\
\hline 27 & - \\
\hline 28 & - \\
\hline
\end{tabular}

the resins, reducing yield strength. Hydrofluoric acid acts by dissolving glass particles, leading to increased surface porosity, which results in increased retention caused by the mechanical bonding agent. An application of this acid at $9.6 \%$ for 2 minutes may be regarded as aggressive since short duration conditioning can dissolve the filling and compromise resin softness. The risks involved in handling hydrofluoric acid and the poor results it yielded may render it less indicated as a surface conditioning agent. This preparation procedure behaved similarly in this study.

Air abrasion showed better results in this study, as well as abrasive grooves. This finding is in agreement with several studies conducted previously. ${ }^{10,23}$ Depending on the type of resin composite treated, differences were observed between preparation methods with abrasive blasting. Durafill's shear force performed better with silane application than without it, unlike Charisma, whose higher values were obtained when silane was not applied. These data corroborate the findings of Martin and Lopez ${ }^{16}$ but contrast with those of DeSchepper, Tate and Power, who reported improved bond strength with the use of silane after abrasive procedures. ${ }^{24}$ Silane application seems to improve the bond strength of the composite after acid etching, blasting and preparation with burs and stones, when it comes to porcelain repairs. ${ }^{25}$ Silane application and the use of adhesives seems to slightly increase bond strength compared to using 
adhesive only. The same results were obtained after subjecting both Durafill and Charisma to sodium bicarbonate blasting and grooves with burs and stone, i.e., an increase in shear strength due to silane in areas etched with phosphoric acid (Figs 5 and 6) ${ }^{26}$ Although Söderholm and Roberts ${ }^{27}$ did not find statistically significant differences in repairing composite surfaces after using silane, this study found an increase in shear strength of surfaces prepared with sodium bicarbonate blasting and grooves with burs and stone in specimens filled with Durafill. Silane may be responsible for the increase in shear forces observed on micro-hybrid resin surfaces.

The action of coupling agents is justified to the extent that it facilitates infiltration of resin composite in microscopic grooves produced in a prior surface preparation. ${ }^{16}$ The process of groove creation enables the detachment of inorganic particles, leaving exposed a deeper region in the composite's resin matrix. Given that there is a structural similarity between orthodontic bonding materials and the resin composites evaluated in this study, shear strength values would be expected which allow the clinical longevity of brackets to be bonded. This increase in shear strength after silane application, however, was not observed in Charisma, which might indicate changes in the exposure of deeper portions of the inorganic matrix material when compared to micro-hybrid composites (Fig 6). Additional studies are needed to substantiate this laboratory finding. ARI differences were observed which may be related to the unique features of the two types of composites and the efficiency shown by different types of surface treatments (Table 4). ARI differences were not found between the use or non-use of silane in many groups, a finding that agrees with some studies. ${ }^{27}$

In terms of the mean yield strength values of the brackets relative to the specimens, it should be noted that according to Lopez, ${ }^{9}$ such yield strength should withstand at least $7.8 \mathrm{MPa}$ of shear force, an amount sufficient to ensure successful bonding in clinical practice.

In this case, only the specimens filled with Durafill after preparation with bicarbonate blasting, bur and stone, reached means that were above the means suggested by Lopez. ${ }^{9}$ As for Charisma, the surface preparation that obtained values greater than $7.8 \mathrm{MPa}$ were the groups that had previously been treated with aluminum oxide blasting, sodium bicarbonate blasting, bur and stone without silane (Table 2). Thus, in Durafill micro-particulate restorations of anterior teeth, orth- odontic brackets would be less prone to bond failures if the surfaces were first prepared with bicarbonate blasting, bur or stone, without silane. However, in the case of brackets bonded to esthetic restorations in posterior teeth restored with Charisma micro-hybrid composite, the best surface preparation according to the results would be aluminum oxide and bicarbonate blasting, bur and stone without silane.

There seems to have been operator influence in surface preparation since standard deviation values relative to the mean values were not low, especially in groups prepared with bicarbonate blasting, bur and stone. This suggests that choosing a method for bonding orthodontic brackets onto resin composites can be influenced by the individual orthodontist performing the procedure (Table 2).

\section{CONCLUSIONS}

1. Charisma, the micro-hybrid resin composite, displayed higher yield strength during shear testing of the brackets than Durafill, the micro-particulate resin composite.

2. Silane application improved surface preparation of Durafill when performed in conjunction with bicarbonate blasting and grooves with bur and stone.

3. When performed on Charisma, silane application worsened the means obtained for the yield strength of orthodontic brackets in all preparation surfaces, with the exception of phosphoric acid.

4. Surface preparation with bicarbonate blasting, bur and stone experienced greater operator influence than others.

5. Surface treatment with sodium bicarbonate blasting, bur and stone in both types of resin composites tested showed a mean yield strength greater than $7.8 \mathrm{MPa}$, a value normally recommended and sufficient to ensure successful bonding in clinical practice.

\section{ACKNOWLEDGEMENTS}

To Drs Felipe A. R. Carvalho and Rhita C.C. Almeida for their collaboration in this work. To Morelli Ortodontia for donating the materials used in this study. To Rio de Janeiro State Foundation for Research Support (FAPERJ) for their financial support. Post-doctoral project Grant No. 152.022/2007 (E26/101.056/2007). 


\section{REFERENCES}

1. McKiernan EX, Jones ML. Psychological profiles and motives of adults seeking orthodontic treatment. Int J Adult Orthodon Orthognath Surg. 1992:7(3):187-98.

2. Salonen L, Mohlin B, Gotzlinger B, Helden L. Need and demand for orthodontic treatment in an adult Swedish population. Eur J Orthod. 1992:14(5):359-68.

3. Andreasen JO. Traumatic injuries of the teeth. 2nd ed. Copenhagen: Munksgaard; 1981.

4. Harari D, Shapira-Davis S, Gillis I, Roman I, Redlich M. Tensile bond strength of ceramic brackets bonded to porcelain facets. Am J Orthod Dentofacial Orthop. 2003:123(5):551-4.

5. Kao EC, Boltz KC, Johnston WM. Direct bonding of orthodontic brackets to porcelain veneer laminates. Am J Orthod Dentofacial Orthop. 1988;94(6):458-68.

6. Zachrisson YO, Zachrisson BU, Buyukyilmaz T. Surface preparation for orthodontic bonding to porcelain. Am J Orthod Dentofacial Orthop. 1996:109(4):420-30

7. Schwartz RE, Tyas MJ, West VC. The bonding of orthodontic brackets to composite resin surfaces. Current note No. 71. Aust Dent J. 1990;35(5):472-3.

8. Lai PY, Woods MG, Tyas MJ. Bond strengths of orthodontic brackets to restorative resin composite surfaces. Aust Orthod J. 1999;15(4):235-45.

9. Lopes Jl. Retentive shear strengths of various bonding attachment bases. Am J Orthod. 1980;77(6):669-78

10. Swift EJ Jr, Le Valley BD, Boyer DB. Evaluation of new methods for composite repair. Dent Mater. 1992:8(6):362-5.

11. Melo MA, Moysés MR, Santos SG, Alcântara CE, Ribeiro JC. Effects of different surface treatments and accelerated artificial aging on the bond strength of composite resin repairs. Braz Oral Res. 2011;25(6):485-91.

12. Boyer DB, Chan KC, Torney DL. The strength of multilayer and repaired composite resin. J Prosthet Dent. 1978 Jan;39(1):63-7.

13. Miranda MS, Dias KRC, Correia SCS, Capanema RE. Efeito do jato de bicarbonato de sódio sobre a superfície de materiais restauradores estéticos. Rev Bras Odontol. 2003:60:240-3.

14. Söderholm KL. Flexure strength of five one component adhesives under simulated pulpal pressure. Oper Dent. 1999;24:36-49.
15. Jafarzadeh KTS, Erfan M, Rakhshan V, Aghabaigi N, Tabatabaei FS. An in vitro assessment of the effects of three surface treatments on repair bond strength of aged composites. Oper Dent. 2011;36(6):608-17.

16. Martín CL, Lopez SG. The effect of various surface treatments and bonding agents on the repaired strength of heat-treated composites. J Prosthet Dent. 2001:86(5):481-8.

17. Cal Neto J, Miguel JAM. Uma análise dos testes in vitro de força de adesão em Ortodontia. Rev Dental Press Ortod Ortop Facial. 2004;9(4):44-51.

18. Artun J, Bergland S. Clinical trial with crystal growth condiotining as an alternative to acid etch enamel pretreatment. Am J Orthod. 1984 Apr:85(4):333-40

19. Kupiecka KA, Bakmeier WW. Laboratory evaluation of surface treatments for composite repair. Oper Dent. 1996;21(2):59-62.

20. Puckett AD, Holder R, O'Hara JW. Strength of posterior composite repairs using different composite/bonding agent combinations. Oper Dent. 1991:16(4):136-40.

21. Turner CW, Meiers JC. Repair for an aged, contaminated indirect composite resin with a direct, visible light cured composite resin. Oper Dent. 1993:18(5):187-94

22. Rinastiti M, Özcan M, Siswomihardjo W, Busscher HJ. Effects of surface conditioning on repair bond strengths of non-aged and aged microhybrid, nanohybrid, and nanofilled composite resins. Clin Oral Investig. 2011;15(5):625-33.

23. Staxrud F, Dahl JE. Role of bonding agents in the repair of composite resin restorations. Eur J Oral Sci. 2011;119(4):316-22.

24. Moncada G, Angel P, Fernandez E, Alonso P, Martin J, Gordan VV. Bond strength evaluation of nanohybrid resin-based composite repair. Gen Dent. 2012;60(3):230-4

25. Stangel I, Nathanson D, Hsu CS. Shear strength of the composite bond to etched porcelain. J Dent Res. 1987;66(9):1460-5.

26. Kimyai S, Mohammadi N, Navimipour EJ, Rikhtegaran S. Comparison of the effect of three mechanical surface treatments on the repair bond strength of a laboratory composite. Photomed Laser Surg. 2010:28 Suppl 2:S25-30.

27 Sodërholm KL, Roberts ML. Variables influencing the repair strength of dental composites. Scand J Dent Res. 1991;99(2):173-80 